\title{
Long term studies of depression: what is relevant for the physician?
}

\author{
Eric Fakra* \\ David Da Fonseca** \\ Samantha Livolsi*** \\ Chloé Destoppeleire* \\ Christophe Lançon* \\ * General Psychiatry Department, Sainte- \\ Marguerite Hospital, Medical Faculty La \\ Timone, Marseille, France \\ ** Psychiatry department for /children and \\ adolescents/(child and adlescents), Sainte- \\ Marguerite Hospital, Medical Faculty La \\ Timone, Marseille, France \\ *** General Psychiatry Department, Hôpital \\ Montperrin, Aix-En-Provence, France \\ FRANCE
}

\begin{abstract}
Following a meticulous review of long term studies of depression, we conclude that prolonging antidepressant medication after full recovery is clearly beneficial. In this article, we examine recent long term studies that reveal substantial evidence in this sense. However, we advise physicians to keep in mind that this prophylactic effect has been proven for a restricted population, i.e., patients showing recurrent depressive disorders with low comorbidity on axis 1, and having revealed a satisfying response to antidepressant agents during the acute phase of the index episode. This does not mean that antidepressant agents are not useful for patients showing other characteristics, but more studies are needed to assert this possible advantage. We also examine the limited data on chronic forms of depressive disorders.

The effect of long term prescription is believed to be advantageous as long as the medication is taken; it has been demonstrated for up to 5 years.

Full dosage is indicated even if the effect of active drug over placebo persists at lower doses. The differences between antidepressant agents appear minor and physicians should be more concerned about the long term tolerance of these drugs than their efficacy when choosing the appropriate medication for maintenance treatment. Physicians should also be aware of the greater risk of recurrence during the 6 months following the discontinuation of medication. This risk occurs regardless of the total length of prescription. The possibility that recurrence may be mistaken for withdrawal symptoms cannot be ruled out.

Finally, the side-effects of antidepressant drugs are a major concern, particularly when extending the length of prescription. Even though the newer generation medications dis-
\end{abstract}


play a more favorable short-term side-effect profile, the effects of chronic use of these agents are still unclear. Therefore, the decision to extend treatment over several years requires comprehensive discussion with patients and cautious clinical monitoring to identify potential late-onset side effects.

Received 12 August 2005

Accepted 21 July 2006

\section{Introduction}

During the past decades, catamnestic studies have contributed to change in our view of depressive disorders. Psychiatrists now admit that a single depressive episode over a lifetime constitutes an exception rather than a rule ${ }^{1,2}$. The high rates of persistent morbidity, recurrence and death among patients suffering from depression ${ }^{3}$ have highlighted the value of long term psychological and pharmacological treatment.

Surprisingly, there is a large gap between consensual recommendations and the physician's routine practice in long term treatment of depression. Therefore, physicians may be concerned by several questions related to the management of this disease, particularly during the maintenance phase.

This article is a meticulous review of recent long term studies of depression in which we will try to answer to several questions:

What evidence do we have that prophylactic treatment is effective?

How should we choose between individual drugs?
What is the optimal duration of drug prescription?

Finally, what is the risk of lasting prescription of antidepressant agents?

\section{Definitions}

First of all, it should be noted that all long term studies on depression concern one type of depression: major depressive disorders. Major depressive disorders are major depressive episodes touching patients that are not suffering from schizophrenia or bipolar disorders. Therefore, other forms of depression such as minor depression or subsyndromic episodes are not covered in these studies. In this review, we also looked at chronic forms of depression (see Results section, Chronic Depression paragraph) which are not included in the definition of major depressive disorders. However chronic forms of depression can raise similar problems of management.

In order to describe the course of depressive episodes, consensual definitions have been proposed for the different stages of the illness and their corresponding treatment phases ${ }^{4}$.

\begin{tabular}{|c|c|c|}
\hline Illness stage & Definition & Treatment phase \\
\hline Acute phase & DSM IV criteria & Acute treatment phase \\
\hline Remission & $\begin{array}{l}\text { Improvement of sufficient amplitude } \\
\text { on psychometric scales (see table 1) }\end{array}$ & Continuation phase \\
\hline Full recovery & $\begin{array}{l}\text { Definitive ending of the depressive } \\
\text { disorder (remission }>n \text { months) }\end{array}$ & $\begin{array}{l}\text { Prophylactic or maintenance } \\
\text { phase }\end{array}$ \\
\hline
\end{tabular}


A relapse is a new depressive episode which occurs after remission, that is, during the continuation phase.

A recurrence is a new depressive episode which occurs after full recovery, that is, during the maintenance phase.

Long term drug treatment includes continuation and maintenance treatment.

The difference between continuation and maintenance treatment might appear arbitrary and may not replicate underlying biological processes, but most authors believe that a four to six month remission period should occur before a recurrence is diagnosed. This issue will be thoroughly discussed later.

Consequently, current guidelines regarding treatment recommend four to nine months of continuation antidepressant therapy following the remission of acute symptoms to allow total resolution of an episode ${ }^{5}$.

Though the practice is fairly homogeneous concerning the prescription of continuation treatment, the situation is very different for maintenance treatment. The exact indication, dosage and total duration of treatment is not consensual and a great disparity exists between recommendations and usual practice. In this context, it is therefore essential to discern what information can be construed from long term studies.

\section{Methodological issues}

Before analysing the results yielded by long term studies, a number of methodological differences need to be pointed out as methodological disparities between trials make interpretation difficult.
All long term studies share a first stage where subjects, after selection, receive treatment during the acute phase of their depressive episode. Selection biases are a major issue, which will be discussed in detail in section 5 .

One of the most crucial points is the time after which randomisation is undertaken. Though all studies proceed by this necessary first phase where every patient entering the trial must achieve remission under treatment, only a limited number of these trials continue on to a second requisite phase of maintenance treatment. Thus randomisation can occur directly after the acute phase or after maintenance treatment. In the former case, recurrence and relapse are grouped together.

It is certainly problematical to determine when the continuation phase of treatment ends and when the true prophylactic phase begins, but examination of the point at which symptoms reappear in studies of long-term treatment can offer some guidance. Data from these studies show a similar pattern of relapse and recurrence, that is a greater rate of relapse (under placebo but also, to a lesser degree, with antidepressant agents) during the first months following remission. The data of Mindham et al. ${ }^{6}$, one of the first long term studies, account for a rate of relapse superior to $40 \%$ during the first 16 weeks. This number is consistent with the results of Prien and Kupfer ${ }^{7}$, who retrospectively examined relapse and recurrence rates with placebo in an earlier study that continued for 2 years. The authors discovered a high rate of relapse in the first 16 weeks $(44 \%)$, the peak rate taking place in the first 8 weeks (38\%). Additionally, if one looks closely at the rate of relapse and recurrence in function of time in all long term studies, it appears that the patterns of relapse and recurrence are highly similar: 
there is a first phase with a high rate of relapse, during approximately 5 to 6 months after remission. Then, the rate of recurrence tends to be much more stable. The first phase corresponds to the length of time defining the continuation phase.

Another important issue is the length of the treatment phases. In the acute phase of treatment for instance, some studies will consider all patients who have reached remission, regardless of the time taken to achieve this condition, whereas other studies will assign a fixed period (6 or 8 weeks for example) after which the assessment is completed and patients who do not meet the remission criteria will be excluded from the trial. This introduces a large bias since, as we will see later, initial response to treatment is a major prognostic of relapse and recurrence. For the trials that comprise a maintenance phase, the length of this period may also be variable, fluctuating from 15 to 24 weeks.

Finally, the last and perhaps most important controversy concerns the definition of remission, which is of course fundamental as this key criteria constitutes a "filter" through which patients are selected for the trial. This definition, like the definition of recurrence, can differ significantly between studies (Table I).

\section{Results of published studies}

\section{Pharmacological nature of maintenance treatment}

The first and probably the most astonishing result is a remarkably stable advantage of treatment over placebo in the prevention of recurrence. We can see in table 2 that treatment prevents roughly $50 \%$ of the recurrences that occur under placebo, regardless of the duration of the study or the pharmacological nature of the antidepressant drug. It is noteworthy that this constant result is not influenced by the presence or absence of the different biases we discussed previously.

We might therefore think that all antidepressant drugs are equivalent in the prevention of recurrent episodes. But we must keep in mind that most of these trials used the same drug during the entire study, which means that a given drug is appropriate for prophylaxis only if it has shown sufficient effectiveness to enable remission during the acute phase and, in most cases, to sustain this remission during the consolidation phase.

The different prophylactic effects between antidepressant agents has been directly analysed in studies comparing several drugs in the same trial (see Table III)

Claghorn et al. ${ }^{8}$ proposed one of the first long-term studies with two antidepressant drugs. Paroxetine and imipramine were compared to placebo after a first acute phase of 6 weeks where patients obtained remission. The next stage did not include any continuation phase. The follow-up lasted one year. Results showed a superior efficacy of both antidepressant drugs over placebo. However, the number of drop outs due to side effects was twice superior in the imipramine group, suggesting that SSRI are better tolerated, especially in long term prophylaxis.

Franchini et al..$^{9}$ compared in double bind two SSRI, sertraline and fluvoxamine, on long term efficacy during a 24 month follow-up. Patients presenting recurrent major depressive episodes were first treated during the acute index episode in an open phase. The majority of patients $(77 \%)$ received tricyclics, others benefited from SSRIs, IMAO 
Table I

Definition variation between long term studies.

\begin{tabular}{|c|c|c|c|c|}
\hline Studies & $\begin{array}{l}\text { Depressive } \\
\text { antecedents }\end{array}$ & $\begin{array}{l}\text { Inclusion } \\
\text { criteria }\end{array}$ & $\begin{array}{l}\text { Remission } \\
\text { criteria }\end{array}$ & $\begin{array}{l}\text { Recurrence } \\
\text { criteria }\end{array}$ \\
\hline Montgomery (1988) & $\begin{array}{l}\geq 1 \mathrm{MDE} \text { in the } \\
\text { previous } 5 \text { years }\end{array}$ & HDRS > 18 & $\begin{array}{l}\text { HDRS }<12 \\
\text { HDRS }<8 \text { to enter } \\
\text { prophylaxis period }\end{array}$ & HDRS $>18$ \\
\hline Frank (1990) & $\geq 3$ previous MDE & $\begin{array}{l}\text { HDRS }>15 \\
\text { RSD }>7\end{array}$ & $\begin{array}{l}\mathrm{HDRS}<7 \\
\mathrm{RSD}<5\end{array}$ & $\begin{array}{l}\text { HDRS }>15 \\
\text { RSD }>7\end{array}$ \\
\hline Robinson (1991) & $\begin{array}{l}\text { Antecedent of minor } \\
\text { or MDE }\end{array}$ & $\begin{array}{l}\text { HDRS }>18 \\
\text { RSD }>7\end{array}$ & $\begin{array}{l}\text { HDRS }<10 \\
\text { GAS }>70 \\
\text { RSD }<5\end{array}$ & $\begin{array}{l}\text { HDRS }>18 \\
R S D>7\end{array}$ \\
\hline Kupfer (1992) & $\geq 3$ previous MDE & $\begin{array}{l}\mathrm{HDRS}>15 \\
\mathrm{RSD}>7\end{array}$ & $\begin{array}{l}\text { HDRS }<7 \\
\mathrm{RSD}<5\end{array}$ & $\begin{array}{l}\mathrm{HDRS}>15 \\
\mathrm{RSD}>7\end{array}$ \\
\hline Terra (1998) & $\begin{array}{l}\geq 2 \text { previous MDE in } \\
\text { the last } 5 \text { years }\end{array}$ & MADRS > 25 & $\begin{array}{l}\text { MADRS }<10 \\
\text { CGI }<2\end{array}$ & $\begin{array}{l}5 \text { criteria in } \\
\text { DSM 3R }\end{array}$ \\
\hline Rouillon (2000) & $\begin{array}{l}\geq 2 \text { previous MDE in } \\
\text { the last } 3 \text { years }\end{array}$ & HDRS > 18 & HSRD $<12$ & HDRS > 18 \\
\hline Gilaberte (2001) & $\begin{array}{l}\geq 1 \text { previous } \mathrm{MDE} \text { in } \\
\text { the last } 5 \text { years }\end{array}$ & $\begin{array}{l}\text { HDRS } 17>18 \\
\text { CGI }>4\end{array}$ & $\begin{array}{l}\text { HDRS } 17<8 \\
\text { CGI }<2\end{array}$ & $\begin{array}{l}\text { HDRS } 17>18 \\
\text { CGI }>4\end{array}$ \\
\hline Hochstrasser (2001) & $\begin{array}{l}\geq 2 \text { previous } \mathrm{MDE}, \\
\text { last one in the last } \\
5 \text { years }\end{array}$ & MADRS > 22 & MADRS $<11$ & MADRS > 22 \\
\hline Klysner (2002) & $\begin{array}{l}\text { Elderly patients } \\
\text { Unipolar MD (DSM 4) }\end{array}$ & MADRS > 22 & MADRS $<11$ & MADRS > 22 \\
\hline Wilson (2003) & $\begin{array}{l}\text { Elderly patients } \\
\text { Major depressive } \\
\text { disorder (DSM 3R) }\end{array}$ & $\begin{array}{l}\text { HDRS } 17>18 \\
\text { AGECAT }>3 \\
\text { MMSE }>11\end{array}$ & $\begin{array}{l}50 \% \text { reduction in } \\
\text { baseline HRSD } \\
\text { HDRS } 17<10\end{array}$ & HDRS $17>13$ \\
\hline Lepine (2004) & $\begin{array}{l}\geq 3 \text { previous MDE, } \\
\text { last one in the last } 4 \text { years } \\
\text { Most recent MDE } \\
\text { within } 6 \text { months } \\
\text { of study }\end{array}$ & $\begin{array}{l}\text { Based on items of } \\
\text { DSMIV and } \\
\text { MADRS (sadness, } \\
\text { depressed mood) }\end{array}$ & $\begin{array}{l}\text { Based on items of } \\
\text { DSMIV and } \\
\text { MADRS (sadness, } \\
\text { depressed mood) }\end{array}$ & $\begin{array}{l}\text { DSM IV criteria, } \\
\text { Clinician's } \\
\text { opinion }\end{array}$ \\
\hline Reynolds (2006) & $\begin{array}{l}\text { Elderly patients } \\
\text { Major depressive disorder } \\
\text { (DSM 4) }\end{array}$ & HDRS $17>17$ & $\begin{array}{l}\text { HDRS } 17<10 \\
/(\text { on }) / \text { for/ } 3 \\
\text { consecutive weeks }\end{array}$ & HDRS $17>15$ \\
\hline
\end{tabular}

Abbreviations:

MDE: Major depressive disorder

HDRS: Hamilton Depression Rating Scale score; HDRS 17: 17 items Hamilton Depression Rating Scale score MADRS: Montgomery and Asberg Depression Rating Scale score

RSD: Raskin Severity of Depression score

CGI: Clinical Global Impression score

AGECAT: Geriatric Mental State

A or combined drug treatments. After a four-month continuation phase and a 3week wash-out period, patients were randomly attributed to one of the two treatment groups. Both treatments showed similar tolerance and survival rates.
Montgomery et al. ${ }^{10}$ compared mirtazapine and amitriptyline in a double-bind placebo-controlled study. Here the long term study design was entirely different as it was an extension of a double-blind placebocontrolled study of acute treatment. After 
remission, patients were given the possibility of continuing the same treatment for up to two years. Authors noted an advantage of mirtazapine over amitriptyline in preventing relapse in the survival analysis, but not in the number of relapses. It should be noted that there was an equivalent number of withdrawals in the two groups due to side effects, and that both mean dosages of amitriptyline and mirtrazapine were relatively low (137.5 mg and $22.8 \mathrm{mg}$ respectively), possibly sub-optimal.
Finally, Bump et al. ${ }^{11}$ conducted a study with elderly patients, comparing nortriptyline to paroxetine. Here, patients were randomly assigned to one of the two treatment groups during the acute phase. After this first stage, patients were offered the opportunity to continue in an open continuation and maintenance treatment for an additional 18 months open trial. Preliminary data showed that both paroxetine and nortriptyline had comparable efficacy in preventing relapse and recurrence, and time before relapse ${ }^{12}$.

Table II

Recurrence rates in long term studies.

\begin{tabular}{|c|c|c|c|c|c|c|c|}
\hline \multirow[t]{2}{*}{ Studies } & \multirow{2}{*}{$\begin{array}{l}\text { Number } \\
\text { of subjects }\end{array}$} & \multicolumn{3}{|c|}{ Length of treatment phase } & \multirow[t]{2}{*}{ Drug } & \multicolumn{2}{|c|}{ Recurrence rate } \\
\hline & & Acute & Contin & Mainten & & Drug & Placebo \\
\hline Montgomery (1988) & $\begin{array}{c}456 \text { initial } \\
220 \text { maint } \\
182 \text { complete }\end{array}$ & 6 weeks & 18 weeks & 1 year & Fluoxetine & $26 \%$ & $57 \%$ \\
\hline Frank (1990) & $\begin{array}{c}128 \text { maint } \\
106 \text { complete }\end{array}$ & $\begin{array}{l}\text { Until } \\
\text { remission }\end{array}$ & 17 weeks & 3 years & Imipramine & $40 \%$ & $81 \%$ \\
\hline Robinson (1991) & $\begin{array}{c}88 \text { initial } \\
47 \text { maint } \\
35 \text { complete }\end{array}$ & $\begin{array}{l}\text { Until } \\
\text { remission }\end{array}$ & 16 weeks & 2 years & Phenelzine & $29 \%$ & $81 \%$ \\
\hline Kupfer (1992) & $\begin{array}{c}20 \text { maint } \\
19 \text { complete }\end{array}$ & & & $\begin{array}{l}(3-) 5 \\
\text { years }\end{array}$ & Imipramine & $18 \%$ & $67 \%$ \\
\hline Terra (1998) & $\begin{array}{l}436 \text { initial } \\
204 \text { maint }\end{array}$ & 6 weeks & 18 weeks & 1 year & Fluvoxamine & $12.7 \%$ & $35.1 \%$ \\
\hline Rouillon (2000) & $\begin{array}{c}500 \text { initial } \\
214 \text { maint } \\
166 \text { complete }\end{array}$ & $\begin{array}{l}\text { Until } \\
\text { remission }\end{array}$ & 4 months & 1 year & Milnacipran & $16.3 \%$ & $23.6 \%$ \\
\hline Gilaberte (2001) & $\begin{array}{c}253 \text { initial } \\
145 \text { maint } \\
121 \text { complete }\end{array}$ & 8 weeks & 24 weeks & 48 weeks & Fluoxetine & $20 \%$ & $40 \%$ \\
\hline Hochstrasser (2001) & $\begin{array}{c}427 \text { initial } \\
269 \text { maint } \\
264 \text { complete }\end{array}$ & $\begin{array}{l}\text { 6-9 weeks } \\
\text { Until } \\
\text { remission }\end{array}$ & 16 weeks & $\begin{array}{c}48 \text { weeks } \\
\text { (max } 77 \\
\text { weeks) }\end{array}$ & Citalopram & $22 \%$ & $76 \%$ \\
\hline Lepine (2004) & $\begin{array}{c}371 \text { initial } \\
288 \text { maint } \\
165 \text { complete }\end{array}$ & $\begin{array}{l}\text { 4-6 months } \\
\text { followed by } \\
\text { a } 2 \text { months } \\
\text { placebo period }\end{array}$ & & 18 months & Sertraline & $16.9 \%$ & $33.3 \%$ \\
\hline
\end{tabular}

\begin{tabular}{|c|c|c|c|c|c|c|}
\hline \multirow[t]{2}{*}{ Studies } & \multirow{2}{*}{$\begin{array}{l}\text { Number } \\
\text { of subjects }\end{array}$} & \multicolumn{2}{|c|}{ Length of treatment phase } & \multirow[t]{2}{*}{ Drug } & \multicolumn{2}{|c|}{ Recurrence rate } \\
\hline & & Acute & Contin +Mainten & & Drug & Placebo \\
\hline Montgomery (1988) & $172 / 141-135$ & 8 weeks & 1 year & Paroxetine & $16 \%$ & $43 \%$ \\
\hline Versiani (1999) & $\begin{array}{l}283 \text { initial } \\
143 \text { maint }\end{array}$ & 6 weeks & $23+23$ weeks & Riboxetine & $21.8 \%$ & $56 \%$ \\
\hline
\end{tabular}




\begin{tabular}{|c|c|c|c|c|c|c|c|}
\hline \multirow[t]{2}{*}{ Studies } & \multirow{2}{*}{$\begin{array}{l}\text { Number } \\
\text { of subjects }\end{array}$} & \multicolumn{3}{|c|}{ Length of treatment phase } & \multirow[t]{2}{*}{ Drug } & \multicolumn{2}{|c|}{ Recurrence rate } \\
\hline & & Acute & Contin & Mainten & & Drug & Placebo \\
\hline Reynolds (1999) & 41 complete & $\begin{array}{c}\text { Until } \\
\text { remission }\end{array}$ & 16 weeks & 3 years & Nortriptyline & \multicolumn{2}{|c|}{$\begin{array}{r}29 \%(80-120 \mathrm{ng} / \mathrm{l}) \\
40 \%(40-60 \mathrm{ng} / \mathrm{l})\end{array}$} \\
\hline Klysner (2002) & $\begin{array}{c}230 \text { initial } \\
121 \text { maint } \\
121 \text { complete }\end{array}$ & 8 weeks & 16 weeks & $>48$ weeks & Citalopram & $32 \%$ & $67 \%$ \\
\hline Wilson (2003) & $\begin{array}{c}318 \text { initial } \\
113 \text { maint } \\
76 \text { complete }\end{array}$ & 8 weeks & $16-20$ weeks & s 100 weeks & Sertraline & $44.6 \%$ & $54.4 \%$ \\
\hline Reynolds (2006) & $\begin{array}{l}195 \text { initial } \\
116 \text { maint }\end{array}$ & Until remission & 16 weeks & 2 years & $\begin{array}{c}\text { Paroxetine } \\
\text { +/-psychotherapy }\end{array}$ & $36.5 \%$ & $64.2 \%$ \\
\hline
\end{tabular}

Abbreviations:

Initial: number of patients included in the study

Maint: number of patients entering maintenance phase

Complete: number of patients completing the study

Conti: continuation phase

Mainten: maintenance phase

Table III

Long Term Studies Comparing the Effect of Different Antidepressants.

\begin{tabular}{|c|c|c|c|c|c|c|c|}
\hline \multirow[t]{2}{*}{ Studies } & \multirow{2}{*}{$\begin{array}{l}\text { Number } \\
\text { of subjects }\end{array}$} & \multicolumn{3}{|c|}{ Length of treatment phase } & \multirow[b]{2}{*}{ Drugs } & \multirow[b]{2}{*}{$\begin{array}{l}\text { Relapse- } \\
\text { Rec. rate }\end{array}$} & \multirow[b]{2}{*}{ Conclusion } \\
\hline & & Accute & Contin & Mainten & & & \\
\hline $\begin{array}{l}\text { Claghorn } \\
\text { (1993) }\end{array}$ & $\begin{array}{l}717 \\
219 \text { conti }\end{array}$ & 6 weeks & \multicolumn{2}{|c|}{$\begin{array}{l}1 \text { year } \\
\text { double-bind } \\
\text { phase }\end{array}$} & $\begin{array}{l}\text { Paroxetine } \\
\text { Imipramine } \\
\text { Placebo }\end{array}$ & $\begin{array}{r}15 \% \\
4 \% \\
25 \%\end{array}$ & $\begin{array}{l}\text { Parox. and } \\
\text { Imip. > placebo } \\
50 \% \text { more drop- } \\
\text { out with Imip. / } \\
\text { Parox due to } \\
\text { side effect. }\end{array}$ \\
\hline $\begin{array}{l}\text { Franchini } \\
\text { (1997) }\end{array}$ & $\begin{array}{l}77 \\
64 \text { conti }\end{array}$ & \multicolumn{2}{|c|}{4 months } & 24 months & $\begin{array}{l}\text { Fluvoxamine } \\
\text { Sertraline }\end{array}$ & $\begin{array}{l}18.7 \% \\
21.9 \%\end{array}$ & $\begin{array}{l}\text { No significant } \\
\text { difference bet- } \\
\text { ween two treat- } \\
\text { ments }\end{array}$ \\
\hline $\begin{array}{l}\text { Montgomery } \\
\text { (1998) }\end{array}$ & & \multicolumn{3}{|c|}{$\begin{array}{c}6 \text { weeks Up to } 2 \text { years } \\
\text { Randomisation during } \\
\text { all treatment phases }\end{array}$} & & & \\
\hline \multirow{2}{*}{$\begin{array}{l}\text { Bump } \\
(2001)\end{array}$} & 116 & \multicolumn{3}{|c|}{12 weeks 12 weeks 18 months } & & & \\
\hline & $\begin{array}{l}\text { Elderly } \\
\text { patients }\end{array}$ & & $\begin{array}{l}\text { domisati } \\
\text { treatmen }\end{array}$ & $\begin{array}{l}\text { during } \\
\text { phases }\end{array}$ & & & \\
\hline
\end{tabular}

The final results suggested that even if the efficacy of these two drugs was comparable, nortriptyline produced fewer residual depressive symptoms and side-effects.
All together, these results suggest that the prophylactic efficacy of all the antidepressant drugs tested is comparable; the main difference resides in the pattern of toler- 
ance, which appears better with newer antidepressant agents.

\section{Dosage of maintenance treatment}

Another important issue is the determination of the drug dosage necessary to obtain an effective prophylactic effect. The current consensus is to employ the same medication dosage that allowed remission during the acute phase $\mathrm{e}^{13,14,15}$. The studies performed by Frank et al. ${ }^{13,14}$ aimed to assess the benefit of full dose maintenance therapy. In a first study (1990) the authors successfully demonstrated that full doses of antidepressant agents were more appropriate than the conventional low doses stated in previous studies $^{16,17}$. In a second study (1993) Frank et al. directly compared imipramine's prophylactic effect at different dosages in a randomized study. Although the small size of the sample prohibited any definite conclusion, the authors suggested that the full dose of imipramine was more effective than the half dose in preventing recurrences.

Franchini et al. ${ }^{18}$ explicitly assessed this question by comparing the prophylactic effects of paroxetine at two different dosages, without any placebo group. Their results showed that paroxetine had a much better prophylactic effect at $40 \mathrm{mg}$ than at $20 \mathrm{mg}$. Unfortunately, all the patients in this study were given the same dose of $40 \mathrm{mg}$ to attain remission. A considerable bias was therefore introduced since some patients could perhaps have achieved remission with lower doses of paroxetine, but were randomised in the high dosage paroxetine group for the third stage analysis.

Also noteworthy are the data resulting from a large naturalistic study performed by the NIMH collaborative study of the psy- chobiology of depression ${ }^{19}$. The results of this study suggest that the most effective treatment, not considering patients suffering from highly recurrent depressive disorders (i.e. more than 5 previous episodes), is a full dose treatment of limited duration, around 8 months. Of course the observational design of this study limits the extent to which cause and effect associations can be deduced. Nevertheless, these results also raise an important methodological issue: though the most important factor in the risk of recurrence is a history of previous depressive episodes, most long term trials do not distinguish patients based on this criterion. Therefore, patients having 5 or 6 previous episodes are assimilated with patients having only 2 previous episodes. Furthermore, the definition of recurrent depressive disorder may vary considerably between studies (Table I).

However, other studies showed contradictory results: Mindham et al. ${ }^{6}$ found that doses of amitriptilyne lower than those used in the acute phase were effective in continuation treatment, but this was not the case for imipramine.

Montgomery et al. ${ }^{20}$ showed that doses of 20 or $40 \mathrm{mg}$ of Citalopram were similarly effective in preventing relapse.

There are only a few randomized clinical trials in which the maintenance efficacy of different doses of antidepressant agents was compared (Table IV).

Rouillon et al. ${ }^{21}$ suggested that a lower than standard dose of maproptiline could be effective in preventing recurrences. Nevertheless, the lowest dose was less effective than the half-standard dose and the full antidepressant dose was not tested in this study, leaving aside the possibility that the latter could be the optimal dose. 
Table IV

Long Term Studies Comparing the Effect of Different Dosages of Antidepressants.

\begin{tabular}{|c|c|c|c|c|c|c|}
\hline \multirow[t]{2}{*}{ Studies } & \multirow{2}{*}{$\begin{array}{l}\text { Number } \\
\text { of subjects }\end{array}$} & \multicolumn{3}{|c|}{ Length of treatment phase } & \multirow[b]{2}{*}{ Drugs } & \multirow[b]{2}{*}{ Relapse Rec. rate } \\
\hline & & Accute & Contin & Mainten & & \\
\hline \multirow{3}{*}{$\begin{array}{l}\text { Rouillon } \\
\text { (1989) }\end{array}$} & 1339 maint & \multirow[t]{3}{*}{6 weeks } & \multicolumn{2}{|c|}{1 year } & Maprotiline & $75 \mathrm{mg}: 16 \%$ \\
\hline & 1141 complete & & & & Placebo & $37.5 \mathrm{mg}: 23.8 \%$ \\
\hline & & & & & & $\begin{array}{l}\text { Full tablet: } 31.5 \% \\
\text { Half tablet: } 37.5 \%\end{array}$ \\
\hline \multirow[t]{2}{*}{ Frank (1993) } & 29 & \multirow{2}{*}{$\begin{array}{l}\text { Until } \\
\text { remission }\end{array}$} & \multirow[t]{2}{*}{5 months } & \multirow[t]{2}{*}{3 years } & \multirow[t]{2}{*}{ Imipramine } & Full dose: $30 \%$ \\
\hline & 20 & & & & & Half dose: $70 \%$ \\
\hline \multirow{3}{*}{$\begin{array}{l}\text { Franchini } \\
\text { (1998) }\end{array}$} & 99 initial & Until & \multirow[t]{3}{*}{4 months } & \multirow[t]{3}{*}{28 months } & \multirow[t]{3}{*}{ Paroxetine } & $20 \mathrm{mg}: 51.5 \%$ \\
\hline & 72 maint & remission & & & & $40 \mathrm{mg}: 23.5 \%$ \\
\hline & 67 complete & $<6$ weeks & & & & \\
\hline
\end{tabular}

\section{Length of prescription of maintenance treatment}

Finally, the question of the total duration of the prophylactic treatment is still undecided. For many authors this treatment should be prescribed for life in the case of patients showing a high recurrence of depressive illness and/or severe characteristics. This issue cannot be directly corroborated by long-term studies as most of them last a maximum of two years. However, Kupfer et al. ${ }^{15}$ were able to obtain data on the prophylaxy of imipramine treatment after three years of maintenance treatment. This study was the extension of the Pittsburgh study of maintenance therapies in recurrent depression ${ }^{13}$. Patients who completed this last three year trial by receiving active medication were asked to continue a two year additional randomized trial of active medication versus placebo. Despite the low number of subjects, results showed a clear advantage of imipramine over placebo in the prevention of recurrence, thus suggesting that medication can reduce the risk of recurrence as long as it is prescribed. It is also interesting to note that even after three years of active medication, patients who were randomised to placebo, thus discontinuing active medica- tion, showed a maximum risk of recurrence in the first six months of the trial. This latter phenomenon can be explained in different ways. The first would be to consider that active medication provides effective protection for patients vulnerable to depression. Stopping the treatment thus raises the risk of early recurrence. We can also imagine that long term treatment also provides a "suggestive" effect, leading patients who stop medication to feel more vulnerable. Another possibility is that antidepressant drugs provide only a symptomatic action, which enables patients to overcome depressive episodes with less suffering (given that the standard duration of a depressive episode is about six months). For patients showing chronic depression, the discontinuation of long term treatment leads to the re-emergence of symptoms that had been contained by the drug. Finally, the possibility of withdrawal symptoms due to drug discontinuation should also be considered. Withdrawal symptoms have clearly been produced with tricyclic agents ${ }^{22}$ and more recently with $\mathrm{SSRI}^{23}$.

\section{Chronic depression}

Another complex clinical situation is the management of patients presenting chronic 
forms of depression. In the literature reviewed, three types of chronic depression can be distinguished:

- chronic major depressions concern patients presenting the criteria for major depression during at least two years,

- dysthymia refers to patients showing mild depressive characteristics (not fulfilling criteria for chronic major depression or major depression with incomplete remission) which last for at least two years,

- finally, double depression is an episode of major depression which occurs in patients who are suffering from dysthymia.

Three studies have explored these problematic conditions (Table V). Kocsis et al. ${ }^{24}$ focused on patients suffering from chronic forms of depression. In their studies, patients showing chronic major depression, "pure" dysthymia or dysthymia with current major depression (“double depression”), entered a long term trial including a ten week acute phase with desipramine followed by an open treatment continuation phase of 16 weeks. Patients sustaining remission were then randomised to placebo or active medication for up to two years. It should be noted that in contrast to other long term trials, patients showing only partial remission after the first phase (defined by a reduction of at least $50 \%$ on the baseline HAM-D score) could also enter the second and third phases. The results of this study showed a much higher recurrence rate for partial responders $(20 \%$ for patients under medication and $40 \%$ for patients under placebo). Patients sustaining full remission after the maintenance phase displayed a $56 \%$ risk of recurrence under placebo and only a $14 \%$ risk when taking medication. Unfortunately, these risks were not singled out for the different types of chronic depression.

Table V

Recurrence Rates in Chronic Depression.

\begin{tabular}{lclccc} 
Studies & Number of subjects & Length of study & Drug & \multicolumn{2}{c}{ Recurrence rate } \\
\hline Kocsis (1996) & 129 & 2 years & Desipramine & $11 \%$ & $52 \%$ \\
Keller (1998) & 161 & 1 year and a half & Sertraline & $26 \%$ & $50 \%$ \\
Gelenberg (2003) & 165 & 1 year & Nefazodone & $30.3 \%$ & $47.5 \%$ \\
\hline
\end{tabular}

Keller et $a l .{ }^{25}$ conducted a similar trial, this time selecting only patients suffering from a chronic form of major depression (chronic major depression or major depression with dysthymia (double depression). The trial consisted of three phases, but here the acute and continuation phases were also submitted to randomisation. A total of 161 patients successfully responded after a 12 week acute phase and a four month continuation phase under sertraline. Patients were then randomized to the same treatment or to placebo for 76 weeks. Sertraline allowed a significantly greater prophylaxis against placebo and the authors noted that depressive symptoms re-emerged twice as frequently with placebo than with sertraline. The astonishingly low recurrence rate of $23 \%$ in the placebo group raised certain questions. The authors replied that chronic forms of major depression probably represent a lower risk factor of developing subsequent depressive episodes than a history of prior recurrent major depressive disorders. They also sug- 
gest that SSRI could lead to fewer withdrawal symptoms than tertiary amine tricyclics; these withdrawal symptoms can be mistaken for a recurrent depressive disorder and explain the increased rates of recurrence in the placebo treatments of other studies. Lastly, it should be noted that the recurrence criteria used in this study were rather drastic compared to other long term studies.

Finally, Gelenberg et al. ${ }^{26}$ recently studied patients presenting chronic forms of major depression (chronic major depressive disorder, "double depression" or recurrent major depressive disorders with incomplete interepisode recovery). Here again the acute phase was submitted to randomization. Only patients responding sufficiently to active medication were asked to prolong the same treatment during a continuation phase. Following this stage, and in the case of stable thymic response, patients were once again randomized in a 52 week double-blind maintenance phase of nefazodone or placebo. The authors found a significant difference between treatment and placebo in the probability of recurrence, but only when applying a competing-risk model. This model took into account, for instance, the unusual number of patients under placebo who interrupted the trial for reasons other than recurrence.

All of these studies suggest that maintenance treatments also play a significant role in the management of chronic depression. However, chronic forms of depression probably constitute a less important risk factor of recurrence than a history of multiple depressive disorders. The major issue in chronic depression is more probably determining how to obtain a satisfying initial response, rather than /defining/ the prescription duration of antidepressant agents.

The links between major depressive disorders and chronic forms of depression raise an interesting questioning. There may be several ways of considering these links:

A first way is to consider chronic depression as the unfavorable outcome of a depressive episode. Comforting this view, interesting literature on residual symptoms can be quoted. Indeed, since the remission state corresponds to a precise score on psychometric scales, it is possible that some patients are considered as remitted according to these scores, even thought they still present a persistent level of symptoms. However these persistent symptoms may not justify a diagnosis of chronic depression or of dysthymia. Several studies have shown that the presence and variability of these residual symptoms were associated with a higher risk of recurrence ${ }^{27,28}$. These findings thus suggest that there may be a continuum between "complete" remission and chronic depression.

Another approach is to consider that chronic depression constitutes a different form of illness than major depressive disorders. This would be apparent in the outcome and evolution of these different disorders but also in their respective etiopathology. For instance it appears that comorbid personality disorders and vulnerable cognitive processes are much more frequent in the case of chronic depressions ${ }^{29}$. Along this line of thinking, it could be interesting to examine the influence of comorbid personality disorders on the rate of remission ${ }^{30,31}$. Another major issue is to evaluate the benefit of psychotherapy in chronic depression according to the presence of personality disorders. For instance, a study performed by Nemeroff et al. ${ }^{32}$ shows that psychotherapy, compared to antidepressant agents, allows a higher rate of remission in chronic depression with childhood trauma. This is not the case for chronic depression without childhood trauma. 


\section{Are these results applicable to usual practice?}

\section{Value of the initial response}

These results enable us to assert several points:

- patients suffering from recurrent depressive disorders (the patients usually selected in these studies) benefit from a prescription of prophylactic treatment;

- this benefit seems to be approximately the same for all pharmacological treatments;

- this benefit is present as long as the drug is prescribed.

However, due to the selection bias of these trials, these results are limited to two conditions. First, only patients with a high risk of depressive recurrence will benefit from prophylactic treatment since the main risk factor retained in the long term studies is a history of several depressive occurrences. Second, in order to benefit from the prophylactic effect, patients must also show a sufficient initial response to antidepressant drugs since patients not obtaining remission are excluded from these trials.

Initial response to antidepressant treatment is of considerable importance. Stewart et $a l .{ }^{33}$ showed that only patients showing a "true drug" initial response (which is delayed and persistent) benefit from a continuation and maintenance treatment by active medication rather than placebo. Patients showing a "placebo" initial response (which is early and not persistent) had a comparable outcome whether continuing with placebo or active medication. Additionally, patients with a placebo pattern of response relapsed more often, regardless of the nature of treatment used (placebo or active drug). These findings have been confirmed by a recent study ${ }^{34}$ : in this trial, 410 patients were treated with mirtazapine and were then randomized after remission to the same dose of mirtazapine or switched to placebo for the maintenance phase. The relapse rate for 'true-drug in itial response pattern' patients switched to placebo was significantly higher than for 'placebo initial response pattern' patients switched to placebo. Moreover, patients with a 'true-drug initial response pattern' relapsed significantly less when continuing mirtazapine rather than placebo. This was not the case for patients with a 'placebo initial response pattern'.

In a study of elderly patients performed by Dew et al. ${ }^{35}$, the temporal pattern of initial response to acute treatment predicted the risk of recurrence. Thus, for patients showing a prolonged absence of response, maintenance treatment did not show any advantage whereas patients showing rapid initial response had a lower risk of recurrence when maintained under treatment rather than under placebo.

\section{Comorbidity}

The main criticism of long term trials is that "ideal" patients, who may not reflect the individual situations confronted by physicians, are often selected. This factor can be particularly relevant in the case of depressive disorders.

First of all, patients suffering from depressive disorders often show a high comorbidity with other psychiatric conditions. Sanderson et al. ${ }^{36}$, for example, found that about twothirds of a panel of 260 patients with a principal diagnosis of depressive disorder had a least one additional coexisting axis 1 disorder. The most common comorbidity diagnosis is anxiety disorder. More recently, Zimmerman et al. ${ }^{37}$ observed that more than half 
of a large group of depressed outpatients met the full criteria for a current anxiety disorder. Some long term studies include patients presenting a general anxiety disorder, but they usually exclude patients suffering from social phobia, obsessive disorders or other anxiety disorders.

Of course, anxiety disorders are not the only type of depressive comorbidity, and though some associated anxiety disorders may be included, addictive disorders are systematically ruled out. Nevertheless, substance abuse disorders play a significant role in the associated comorbidity of depression. Spaner et al. ${ }^{38}$ showed that nearly one third of individuals with an affective disorder also met the criteria for alcohol dependence. This proportion obviously increases when all types of substance use disorders are considered ${ }^{39}$.

Finally, it should be noted that medical comorbidity is also a frequent condition that is left out of trials. This association could lead to a more severe symptomatology and treatment resistance ${ }^{40}$. In a retrospective study of medically ill subjects treated with antidepressant medication for major depression, Popkin et al. ${ }^{41}$ obtained response rates as low as $40 \%$.

Physicians should therefore keep in mind that the results of the long term trials are valid for a specific population, which includes only patients suffering from depressive disorder with low or no comorbidity.

\section{What is the risk of long term treatment?}

The issue of side-effects has dwindled from its position at the forefront of depression management since the introduction of new antidepressant agents. However, the consensual recommendations that tend to extend the indications and length of antidepressant prescriptions should also encourage a thorough inspection of short-term as well as late appearance side-effects. Numerous studies have confirmed the safer profile and the lower occurrence of side effects claimed for newer compounds ${ }^{42}$. Unlike TCAs, SSRIs induce no, or fewer, anticholinergic, hypotensive or sedating sideeffects. The most common side-effects reported include nausea, headache, vomiting, nervousness, insomnia and sexual dysfunction. These effects are usually moderate and often diminish after the first weeks of treatment (for review $\mathrm{see}^{43}$ ). Dual action antidepressants are also better tolerated than tricyclic antidepressants ${ }^{44}$. As with SSRIs, they do not present the autonomic inconvenience of tricyclics. But here again, sedation, nausea, sexual dysfunction and weight gain are sometimes reported when using these treatments.

Anderson \& Tomenson $^{45}$ conducted a meta-analysis comparing the discontinuation rates with SSRIs and TCA. This work showed that the drop-out rate due to sideeffects was $25 \%$ lower with SSRI than with TCA, whereas the total discontinuation rate was only $10 \%$ better with SSRIs. More recent meta-analyses ${ }^{46,47}$ tend to nuance this finding and seem favourable to a more modest advantage for tolerance of SSRIs compared to TCA.

Managing these side effects is all the more important since they play a major role in adherence to pharmacotherapy. Several studies have shown that adequate information concerning side-effects and good control could allow considerable compliance increase ${ }^{48}$. In addition, respect of guidelines for depression treatment has been shown to 
play a major role in reducing the risk of relapse and recurrence ${ }^{49}$.

In addition to these commonly described side-effects, physicians should be aware of the more dangerous consequences of these pharmacological treatments on the course of the depressive illness. The induction of maniac/hypomaniac symptoms for instance, is a classic risk that is poorly documented. It has been estimated at less than $1 \%$ for strictly unipolar depression, but other authors suggest this risk could attain $10 \%^{50}$. Additionally, some manifestations usually attributed to antidepressants, such as insomnia, nervousness or irritability, could represent some subclinical form of hypomania. Finally, antidepressant agents have also been incriminated in various behavioral changes; though these findings are not substantiated, it has been suggested that these drugs could play a role in inducing suicidal behavior ${ }^{21}$.

It is true that little data exists on the longterm consequences of antidepressants, especially concerning the newer compounds. Apart from the possible modifications of sleep structure, biorhythm and hepatic metabolism, neurobiological changes after chronic use of such agents largely challenge our knowledge. The possibility that distinct patterns of pharmacologic modifications may appear after several years of treatment can not be ruled out and some authors have even suggested that opposing effects could occur in some patients after chronic use of these drugs, leading to an aggravation of the course of depressive illness ${ }^{51}$.

\section{Conclusion}

Long-term studies provide substantial aid to physicians in the management of recur- rent depressive disorders, especially since no consensual guidelines exist on this specific topic.

Following a meticulous review of long term studies of depression, we conclude that prolonging antidepressant medication after recovery is clearly beneficial. The effects of long term prescription are advantageous as long as the medication is taken; it has been demonstrated for up to 5 years. The dosage used in maintenance treatment is the same as that which was effective during the acute phase. Even if the dosage of the antidepressant drug is diminished, it is still more effective than placebo treatment, but to a lesser extent. Physicians should therefore pay particular attention to the long term tolerance of these drugs, probably more so than to their long term efficacy, since the difference in efficacy between drugs seems to be minor.

Considerable efforts to standardize the methods applied in recent trials allow finer comparisons and lead to more reliable conclusions. Nevertheless, these studies concern a limited population and their value is diminished by a lack of data concerning people with comorbidity axis 1 and axis 3 disorders, children and adolescents. The focus of future research should be expanded to include the potential late onset adverse events and withdrawal phenomena that can result from the chronic use of antidepressant drugs.

\section{Acknowledgements}

The authors wish to thank Christine Gard and Magen O'Farrell for their help in correcting the English text. 


\section{References}

1. Hirschfeld RM. Clinical importance of long-term antidepressant treatment. Br J Psychiatry 2001; (Suppl 42): S4-S8.

2. Keller MB, Lavori PW, Mueller TI et al. Time to recovery, chronicity, and levels of psychopathology in major depression. A 5-year prospective follow-up of 431 subjects. Arch Gen Psychiatry 1992; 49: 809-816.

3. Kiloh LG, Andrews G, Neilson M. The long-term outcome of depressive illness. Br J Psychiatry 1988; 153: 752-757.

4. Frank E, Prien RF, Jarrett RB et al. Conceptualization and rationale for consensus definitions of terms in major depressive disorder. Remission, recovery, relapse, and recurrence. Arch Gen Psychiatry 1991; 48: 851-855.

5. American Psychiatric Association. Practive guidelines for major depressive disorder in adults. Am J Psychiatry 1993; 150: 1-26.

6. Mindham RH, Howland C, Shepherd M. An evaluation of continuation therapy with tricyclic antidepressants in depressive illness. Psychol Med 1973; 3: 5-17.

7. Prien RF, Kupfer DJ. Continuation drug therapy for major depressive episodes: how long should it be maintained? Am J Psychiatry 1986; 143: 18-23.

8. Claghorn JL, Feighner JP. A double-blind comparison of paroxetine with imipramine in the long-term treatment of depression. J Clin Psychopharmacol 1993; 13(Suppl): S23- S27.

9. Franchini L, Gasperini M, Perez J, Smeraldi E, Zanardi R. A double-blind study of long-term treatment with sertraline or fluvoxamine for prevention of highly recurrent unipolar depression. J Clin Psychiatry 1997; 58: 104-107.

10. Montgomery SA, Reimitz PE, Zivkov M. Mirtazapine versus amitriptyline in the long-term treatment of depression: a double-blind placebo-controlled study. Int Clin Psychopharmacol 1998; 13: 63-73.

11. Bump GM, Mulsant BH, Pollock BG et al. Paroxetine versus nortriptyline in the continuation and maintenance treatment of depression in the elderly. Depress Anxiety $2001 ; 13: 38-44$.

12. Walters G, Reynolds CF, 3rd, Mulsant BH, Pollock BG. Continuation and maintenance pharmacotherapy in geriatric depression: an open-trial comparison of paroxetine and nortriptyline in patients older than 70 years. J Clin Psychiatry 1999; 60 (Suppl 20): 21-25.

13. Frank E, Kupfer DJ, Perel JM et al. Three-year outcomes for maintenance therapies in recurrent depression. Arch Gen Psychiatry 1990; 47: 1093-1099.
14. Frank E, Kupfer DJ, Perel JM et al. Comparison of full-dose versus half-dose pharmacotherapy in the maintenance treatment of recurrent depression. J Affect Disord 1993; 27: 139-145.

15. Kupfer DJ, Frank E, Perel JM et al. Five-year outcome for maintenance therapies in recurrent depression. Arch Gen Psychiatry 1992; 49: 769-773.

16. Glen AI, Johnson AL, Shepherd M. Continuation therapy with lithium and amitriptyline in unipolar depressive illness: a randomized, double-blind, controlled trial. Psychol Med 1984; 14: 37-50.

17. Prien RF, Kupfer DJ, Mansky PA et al. Drug therapy in the prevention of recurrences in unipolar and bipolar affective disorders. Report of the NIMH Collaborative Study Group comparing lithium carbonate, imipramine, and a lithium carbonate-imipramine combination. Arch Gen Psychiatry 1984; 41: 1096-1104.

18. Franchini L, Zanardi R, Gasperini M, Smeraldi E. Two-year maintenance treatment with citalopram, $20 \mathrm{mg}$, in unipolar subjects with high recurrence rate. J Clin Psychiatry 1999; 60: 861-865.

19. Dawson R, Lavori PW, Coryell WH, Endicott J, Keller MB. Maintenance strategies for unipolar depression: an observational study of levels of treatment and recurrence. J Affect Disord 1998; 49: 31-44.

20. Montgomery SA, Rasmussen JG, Tanghoj P. A 24week study of $20 \mathrm{mg}$ citalopram, $40 \mathrm{mg}$ citalopram, and placebo in the prevention of relapse of major depression. Int Clin Psychopharmacol 1993; 8: 181-188.

21. Rouillon F, Warner B, Pezous N, Bisserbe JC. Milnacipran efficacy in the prevention of recurrent depression: a 12-month placebo-controlled study. Milnacipran recurrence prevention study group. Int Clin Psychopharmacol 2000; 15: 133-140.

22. Garner EM, Kelly MW, Thompson DF. Tricyclic antidepressant withdrawal syndrome. Ann Pharmacother 1993; 27: 1068-1072.

23. Zajecka J, Tracy KA, Mitchell S. Discontinuation symptoms after treatment with serotonin reuptake inhibitors: a literature review. J Clin Psychiatry 1997; 58: 291-297.

24. Kocsis JH, Friedman RA, Markowitz JC et al. Maintenance therapy for chronic depression. A controlled clinical trial of desipramine. Arch Gen Psychiatry 1996; 53: 769-774.

25. Keller MB, Kocsis JH, Thase ME et al. Maintenance phase efficacy of sertraline for chronic depression: a randomized controlled trial. JAMA 1998; 280: 1665-1672.

26. Gelenberg AJ, Trivedi MH, Rush AJ et al. Randomized, placebo-controlled trial of nefazodone maintenance 
treatment in preventing recurrence in chronic depression. Biol Psychiatry 2003; 54: 806-817.

27. Karp JF, Buysse DJ, Houck PR, Cherry C, Kupfer DJ, Frank E. Relationship of variability in residual symptoms with recurrence of major depressive disorder during maintenance treatment. Am J Psychiatry 2004; 161: 18771884.

28. Paykel ES. Historical overview of outcome of depression. Br J Psychiatry 1994; (Suppl): S6-S8.

29. Beck AT. Depression: Causes and Treatment. Philadelphia: University of Pennsylvania Press; 1967.

30. Hirschfeld RM, Russell JM, Delgado PL et al. Predictors of response to acute treatment of chronic and double depression with sertraline or imipramine. J Clin Psychiatry 1998; 59: 669-675.

31. Russell JM, Kornstein SG, Shea MT et al. Chronic depression and comorbid personality disorders: response to sertraline versus imipramine. J Clin Psychiatry 2003; 64: 554-561.

32. Nemeroff CB, Heim CM, Thase ME et al. Differential responses to psychotherapy versus pharmacotherapy in patients with chronic forms of major depression and childhood trauma. Proc Natl Acad Sci USA 2003; 100: 1429314296.

33. Stewart JW, Quitkin FM, McGrath PJ et al. Use of pattern analysis to predict differential relapse of remitted patients with major depression during 1 year of treatment with fluoxetine or placebo. Arch Gen Psychiatry 1998; 55: 334-343.

34. Nierenberg AA, Quitkin FM, Kremer C, Keller MB, Thase ME. Placebo-controlled continuation treatment with mirtazapine: acute pattern of response predicts relapse. Neuropsychopharmacology 2004; 29: 1012-1018.

35. Dew MA, Reynolds CF, 3rd, Mulsant B et al. Initial recovery patterns may predict which maintenance therapies for depression will keep older adults well. J Affect Disord 2001; 65: 155-166.

36. Sanderson WC, Beck AT, Beck J. Syndrome comorbidity in patients with major depression or dysthymia: prevalence and temporal relationships. Am J Psychiatry 1990; 147: 1025-1028.

37. Zimmerman M, McDermut W, Mattia JI. Frequency of anxiety disorders in psychiatric outpatients with major depressive disorder. Am J Psychiatry 2000; 157: 13371340 .

38. Spaner D, Bland RC, Newman SC. Epidemiology of psychiatric disorders in Edmonton. Major depressive disorder. Acta Psychiatr Scand Suppl 1994; 376: 7-15.

39. Regier DA, Farmer ME, Rae DS et al. Comorbidity of mental disorders with alcohol and other drug abuse.
Results from the Epidemiologic Catchment Area (ECA) Study. JAMA 1990; 264: 2511-2518.

40. Consoli SM. [Depression and associated organic pathologies, a still under-estimated comorbidity. Results of the DIALOGUE study]. Presse Med 2003; 32: 10-21.

41. Popkin MK, Callies AL, Mackenzie TB. The outcome of antidepressant use in the medically ill. Arch Gen Psychiatry 1985; 42: 1160-1163.

42. Masand PS, Gupta S. Long-term side effects of newer-generation antidepressants: SSRIS, venlafaxine, nefazodone, bupropion, and mirtazapine. Ann Clin Psychiatry 2002; 14: 175-182.

43. Peretti S, Judge R, Hindmarch I. Safety and tolerability considerations: tricyclic antidepressants vs. selective serotonin reuptake inhibitors. Acta Psychiatr Scand Suppl 2000; 403: 17-25.

44. Gupta RK, Tiller JW, Burrows GD. Dual action antidepressants and some important considerations. Aust N Z J Psychiatry 2003; 37: 190-195.

45. Anderson IM, Tomenson BM. Treatment discontinuation with selective serotonin reuptake inhibitors compared with tricyclic antidepressants: a meta-analysis. BMJ 1995; 310: 1433-1438.

46. Anderson IM. Selective serotonin reuptake inhibitors versus tricyclic antidepressants: a meta-analysis of efficacy and tolerability. J Affect Disord 2000; 58: 19-36.

47. Hotopf M, Hardy R, Lewis G. Discontinuation rates of SSRIs and tricyclic antidepressants: a meta-analysis and investigation of heterogeneity. Br J Psychiatry 1997; 170: 120-127.

48. Lin EH, Von Korff M, Ludman EJ et al. Enhancing adherence to prevent depression relapse in primary care. Gen Hosp Psychiatry 2003; 25: 303-310.

49. Melfi CA, Chawla AJ, Croghan TW, Hanna MP, Kennedy S, Sredl K. The effects of adherence to antidepressant treatment guidelines on relapse and recurrence of depression. Arch Gen Psychiatry 1998; 55: 1128-1132.

50. Sechter D. [Long-term clinical effects of antidepressive agents]. Encephale 1995; 21 (Spec No 2): 35-38.

51. Fava GA. Can long-term treatment with antidepressant drugs worsen the course of depression? J Clin Psychiatry 2003; 64: 123-133.

Address for correspondence:

\section{Eric Fakra}

Service de Psychiatrie du Pr. Azorin, Hopital SainteMarguerite, 13274 Marseille Cedex 09, France

E-mail address : Eric.FAKRA@mail.ap-hm.fr

Phone: 33491744082

Fax: 33491744578

FRANCE 